\title{
Mucilaginibacter myungsuensis sp. nov., isolated from a mesotrophic artificial lake
}

Correspondence

Kiseong Joh

ksjoh@hufs.ac.kr

\author{
Yochan Joung and Kiseong Joh
}

Department of Bioscience and Biotechnology, Hankuk University of Foreign Studies, Wangsan, Yongin, Gyeonggi 449-791, Republic of Korea
A non-motile, pale-yellow bacterium, designated strain $\mathrm{HMD} 1056^{\top}$, was isolated from an artificial lake located within the campus of Hankuk University of Foreign Studies, Yongin, Korea. The major fatty acids were summed feature 3 (iso- $\mathrm{C}_{15: 0} 2-\mathrm{OH}$ and/or $\left.\mathrm{C}_{16: 1} \omega 7 c ; 49.1 \%\right)$ and iso- $\mathrm{C}_{15: 0}(22.4 \%)$. The major respiratory quinone was MK-7. The DNA G+C content was 46.9 mol\%. A phylogenetic

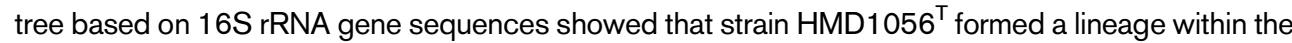
genus Mucilaginibacter and was closely related to the type strains of Mucilaginibacter ximonensis (95.4\% sequence similarity), Mucilaginibacter kameinonensis (94.5\%) and Mucilaginibacter paludis (93.4\%). On the basis of the evidence presented in this study, strain HMD1056 ${ }^{\top}$ represents a novel species of the genus Mucilaginibacter, for which the name Mucilaginibacter myungsuensis sp. nov. is proposed. The type strain is HMD1056 ${ }^{\top}\left(=\right.$ KCTC $22746^{\top}=$ CECT $\left.7550^{\top}\right)$.
The genus Mucilaginibacter was proposed by Pankratov et al. (2007) and members of the genus are characterized by the ability to produce large amounts of extracellular polymeric substances and to hydrolyse pectin, xylan, pullulan and starch. Strains of Mucilaginibacter may also contain iso$\mathrm{C}_{15: 0}$ as the major fatty acid and other hydroxy fatty acids as major components. At the time of writing, the genus Mucilaginibacter includes 12 species with validly published names: Mucilaginibacter paludis (the type species) and $M$. gracilis (Pankratov et al., 2007), M. kameinonensis (Urai et al., 2008), M. daejeonensis (An et al., 2009), M. ximonensis (Luo et al., 2009), M. oryzae (Jeon et al., 2009), M. rigui (Baik et al., 2010), M. gossypii and M. gossypiicola (Madhaiyan et al., 2010) and M. frigoritolerans, M. lappiensis and M. mallensis (Männistö et al., 2010). Mucilaginibacter species have been isolated from rice straw, various soils, acidic Sphagnum peat bog, freshwater and lichen.

In the course of a study on the microbial diversity of a mesotrophic artificial lake within the campus of Hankuk University of Foreign Studies in Yongin, Republic of Korea, pale-yellow colonies were isolated on R2A agar at $30{ }^{\circ} \mathrm{C}$ using the standard dilution plating technique. Isolate HMD $1056^{\mathrm{T}}$ was maintained on R2A agar at $30{ }^{\circ} \mathrm{C}$ and the culture was suspended in water containing $20 \%$ glycerol $(\mathrm{w} / \mathrm{v})$ for storage at $-80{ }^{\circ} \mathrm{C}$.

Almost-complete sequences of the 16S rRNA gene were obtained for strain HMD $1056^{\mathrm{T}}$, as described previously (Cho \& Giovannoni, 2003). Identification of phylogenetic neighbours and calculation of pairwise 16S rRNA gene sequence similarity were performed by using the EzTaxon

The GenBank/EMBL/DDBJ accession number for the 16S rRNA gene sequence of strain $\mathrm{HMD}_{1056^{\top}}$ is GQ144415. server (http://www.eztaxon.org/; Chun et al., 2007). Phylogenetic and molecular evolutionary analyses were conducted by using MEGA version 4 (Tamura et al., 2007). Phylogenetic trees were inferred using the maximumlikelihood (Felsenstein, 1981), maximum-parsimony (Fitch, 1971) and neighbour-joining (Saitou \& Nei, 1987) algorithms. The robustness of the topologies for the maximum-likelihood and neighbour-joining trees was evaluated by means of bootstrap analysis (Felsenstein, 1985) based on 1000 resamplings of the sequences. All phylogenetic trees generated in this study indicated that strain HMD $1056^{\mathrm{T}}$ belonged to the genus Mucilaginibacter (Fig. 1). Strain HMD $1056^{\mathrm{T}}$ formed a coherent clade with M. ximonensis $\mathrm{XM}-003^{\mathrm{T}}(95.4 \%)$ within the phylogenetically well-resolved Mucilaginibacter clade. This phylogenetic inference, coupled with 16S rRNA gene sequence similarities of $<97 \%$ (Wayne et al., 1987) between strain HMD $1056^{\mathrm{T}}$ and strains of other Mucilaginibacter species, suggested that the strain should be assigned to the genus Mucilaginibacter as a representative of a novel species.

M. paludis KACC $13450^{\mathrm{T}}$, M. gracilis KACC $13451^{\mathrm{T}}$, M. kameinonensis KCTC $22227^{\mathrm{T}}$ and M. ximonensis KCTC $22437^{\mathrm{T}}$ were used as reference strains for phenotypic analysis and determination of cellular fatty acid profiles. Cell morphology was examined by light microscopy. Gram staining was determined using the bioMérieux Gram stain kit according to the manufacturer's instructions. Anaerobic growth was tested on R2A agar at $25{ }^{\circ} \mathrm{C}$ by using a GasPak EZ anaerobic container system (BD) according to the manufacturer's instructions. Cellular pigments were extracted with acetone/methanol $(1: 1, \mathrm{v} / \mathrm{v})$ and their absorption spectra were determined using a scanning UV/visible spectrophotometer (UV 6101A; Shimadzu). The 


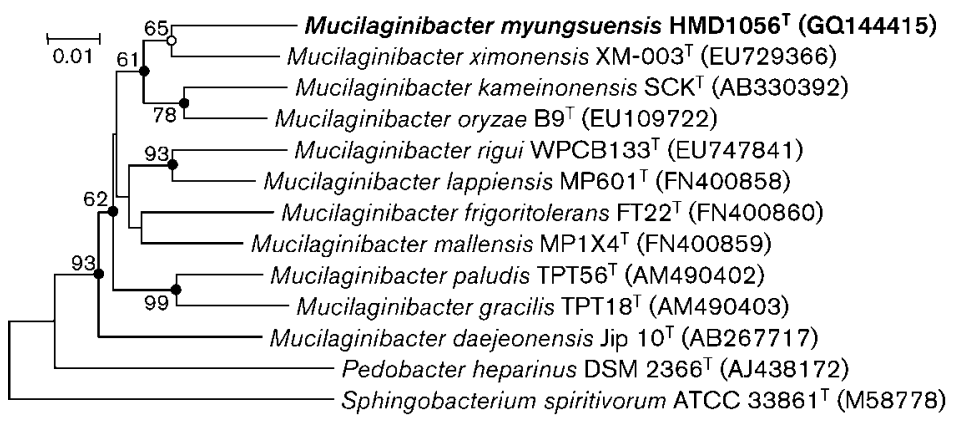

Fig. 1. Neighbour-joining phylogenetic tree based on nearly complete 16S rRNA gene sequences showing the relationships between strain HMD $1056^{\top}$ and strains of the genus Mucilaginibacter. Percentages at nodes are levels of bootstrap support ( $>50 \%$ ) based on neighbour-joining analyses of 1000 resampled datasets. Filled and open circles respectively indicate notes recovered by all three treeing methods or by two treeing methods. Sphingobacterium spiritivorum ATCC $33861^{\top}$ was used as an outgroup. Bar, 0.01 substitutions per nucleotide position. presence of flexirubin-type pigments was investigated by using the bathochromatic shift test with a $\mathrm{KOH}$ solution (Bernardet et al., 2005; Fautz \& Reichenbach, 1980). Catalase and oxidase tests were performed according to standard methods (MacFaddin, 1980). The temperature range and optimum for growth were assessed on MA at 4, $10-30{ }^{\circ} \mathrm{C}$ (at $5{ }^{\circ} \mathrm{C}$ intervals), 37 and $42{ }^{\circ} \mathrm{C}$ over $72 \mathrm{~h}$. The $\mathrm{pH}$ range for growth was determined in $\mathrm{R} 2 \mathrm{~A}$ broth at $20{ }^{\circ} \mathrm{C}$. The medium was adjusted to $\mathrm{pH} 5.0-10.0$ (at intervals of $1.0 \mathrm{pH}$ unit) using $0.1 \mathrm{mM}$ sodium acetate buffer ( $\mathrm{pH}$ 5.0-7.0), $0.1 \mathrm{mM}$ phosphate buffer ( $\mathrm{pH} 7.0$ 8.0 ) and $0.1 \mathrm{mM}$ sodium carbonate buffer $(\mathrm{pH} 9.0-10.0)$. Growth in the presence of $0.5 \%$ and $1.0-5.0 \%$ (at intervals of $1.0 \%) \mathrm{NaCl}(\mathrm{w} / \mathrm{v})$ was also tested in $\mathrm{R} 2 \mathrm{~A}$ broth. Hydrolysis of casein [3\% skimmed milk (Difco), v/v], CMcellulose $[1.0 \%$ CM-cellulose (Sigma), w/v], crystalline cellulose (Whatman No. 1 filter paper, $1 \% \mathrm{w} / \mathrm{v}$ ) and starch $(1.0 \%, \mathrm{w} / \mathrm{v})$ was tested using R2A agar as the basal medium. MacConkey agar (Difco) and DNase test agar (Difco) were used to test for growth and production of DNase, respectively. Other biochemical tests and carbon source oxidation tests were performed using API 20NE, API 50CH and API ZYM strips (bioMérieux) and Biolog GN2 MicroPlates, according to the manufacturers' instructions. The DNA G $+\mathrm{C}$ content was determined by using HPLC (Mesbah \& Whitman, 1989). For fatty acid methyl ester analysis, strain HMD $1056^{\mathrm{T}}$ and the four reference strains were grown on MA at $25^{\circ} \mathrm{C}$ for 3 days and fatty acid methyl esters were extracted and prepared according to the standard protocol of the MIDI/Hewlett Packard Microbial Identification System (Sasser, 1990). Isoprenoid quinones were isolated according to Minnikin et al. (1984) and analysed by HPLC as described by Collins (1985).

Morphological, cultural, physiological and biochemical characteristics of strain HMD $1056^{\mathrm{T}}$ are listed in Table 1 and in the species description. Strain HMD $1056^{\mathrm{T}}$ exhibited a number of phenotypic similarities to species of the genus Mucilaginibacter, including growth temperature range, pale-yellow pigmentation and obligately aerobic growth. However, several characteristics of $\mathrm{HMD} 1056^{\mathrm{T}}$ clearly differentiated this strain from the type strains of Mucilaginibacter species (Table 1).
The fatty acid profile of strain $\mathrm{HMD} 1056^{\mathrm{T}}$ contained summed feature 3 (iso- $\mathrm{C}_{15: 0} 2-\mathrm{OH}$ and/or $\mathrm{C}_{16: 1} \omega 7 c$, $49.1 \%)$ and iso- $\mathrm{C}_{15: 0}(22.4 \%)$ as major components. The complete fatty acid profile of strain $\mathrm{HMD} 1056^{\mathrm{T}}$ is given in Table 2. The major fatty acid profile was similar to those of other Mucilaginibacter species, although there were differences in the relative proportions of some fatty acids (Table 2). The respiratory quinones were MK-7 (major component) and MK-6 (minor), as reported for other members of genus Mucilaginibacter. The DNA G+C content of strain $\mathrm{HMD} 1056^{\mathrm{T}}$ was $46.9 \mathrm{~mol} \%$, a value within the range reported for members of genus Mucilaginibacter. The phenotypic data confirm the phylogenetic affiliation of strain $\mathrm{HMD} 1056^{\mathrm{T}}$ to the genus Mucilaginibacter. Therefore, strain $\mathrm{HMD} 1056^{\mathrm{T}}$ should be classified in the genus Mucilaginibacter as a member of novel species, for which the name Mucilaginibacter myungsuensis sp. nov. is proposed.

\section{Description of Mucilaginibacter myungsuensis sp. nov.}

Mucilaginibacter myungsuensis (myung.su.en'sis. N.L. masc. adj. myungsuensis pertaining to Myungsu, the name of the mesotrophic freshwater lake from which the type strain was isolated).

Cells are Gram-negative, non-motile, aerobic rods, 0.7$0.8 \mu \mathrm{m}$ in diameter and 1.4-1.5 $\mu \mathrm{m}$ long. Colonies on R2A are pale yellow, mucoid, convex and round and approximately $5 \mathrm{~mm}$ in diameter after 2 days at $25^{\circ} \mathrm{C}$. Good growth occurs on blood agar, TSA and R2A agar. No growth occurs on DNA test agar or MacConkey agar. Growth occurs in the presence of $0-1.0 \%(\mathrm{w} / \mathrm{v}) \mathrm{NaCl}$ (optimum 0.5\%), at pH 5-9 (optimum pH 7) and at 10$30{ }^{\circ} \mathrm{C}$ (optimum $30{ }^{\circ} \mathrm{C}$ ). Oxidase and catalase activities and aesculin hydrolysis activity are present, but arginine dihydrolase, lysine decarboxylase, ornithine decarboxylase, tryptophan deaminase and L-phenylalanine deaminase activities are absent. Casein and starch are hydrolysed, but gelatin and tyrosine are not. Citrate is not utilized. Flexirubin-type pigments are produced. In the API ZYM gallery, alkaline phosphatase, esterase (C4), esterase lipase (C8), leucine arylamidase, valine arylamidase, cystine 
Table 1. Differential characteristics of strain $\mathrm{HMD} 1056^{\top}$ and type strains of closely related Mucilaginibacter species

Strains: 1, HMD $1056^{\mathrm{T}}$; 2, M. paludis KACC $13450^{\mathrm{T}}$; 3, M. gracilis KACC $13451^{\mathrm{T}}$; 4, M. kameinonensis KCTC $22227^{\mathrm{T}}$; 5, M. ximonensis KCTC $22437^{\mathrm{T}}$ (data in columns 1-5 from this study unless indicated); 6, M. gossypii Gh-67 ${ }^{\mathrm{T}}$; , M. gossypiicola Gh- $48^{\mathrm{T}}$ (data in columns 6 and 7 from Madhaiyan et al., 2010); 8, M. frigoritolerans FT22 ${ }^{\mathrm{T}}$; 9, M. lappiensis ANJL12 ${ }^{\mathrm{T}}$; 10, M. mallensis MP1X4 ${ }^{\mathrm{T}}$ (data in columns 8-10 from Männistö et al., 2010). + , Positive; w, weakly positive; -, negative; NA, no data available.

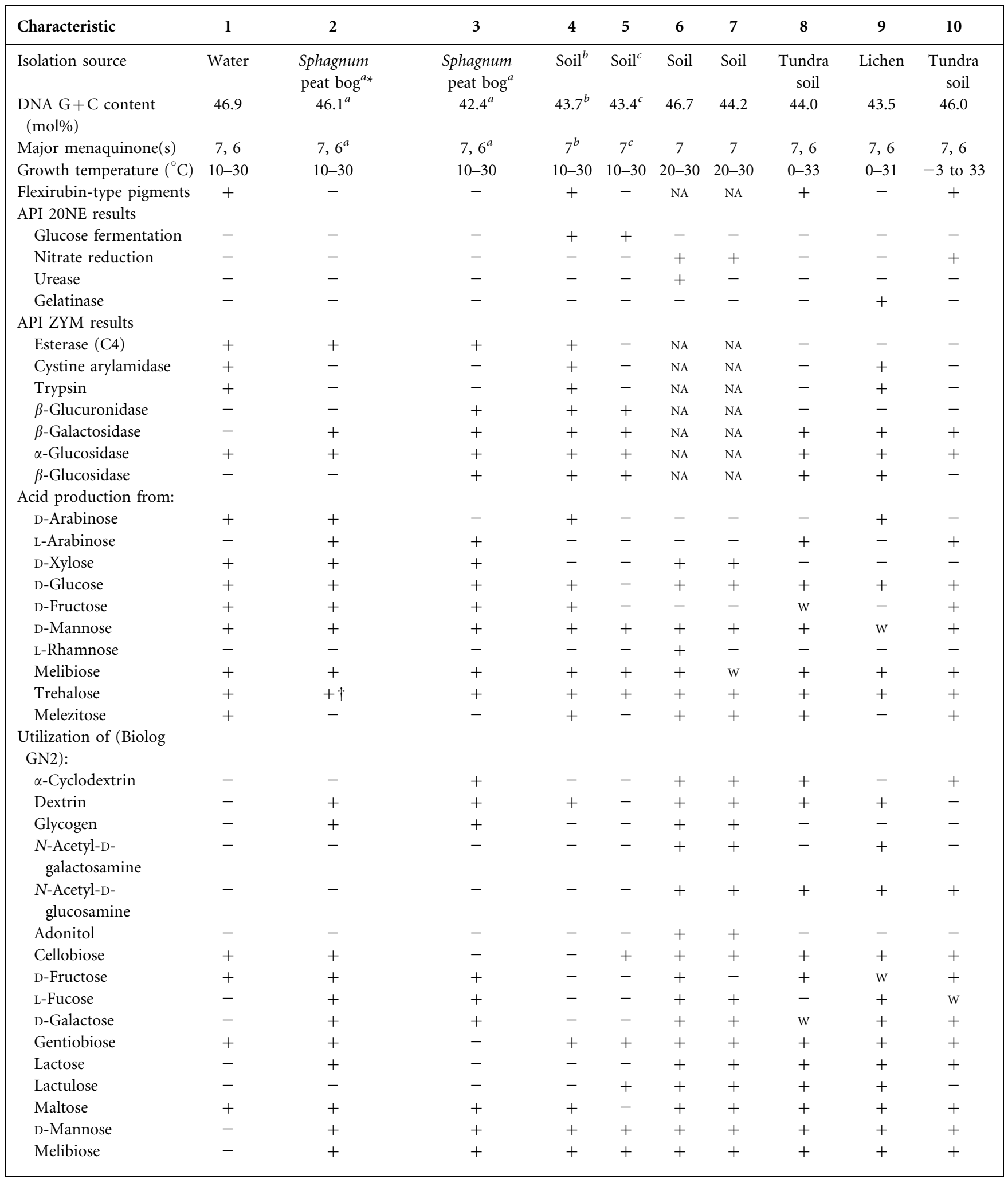


Table 1. cont.

\begin{tabular}{|c|c|c|c|c|c|c|c|c|c|c|}
\hline Characteristic & 1 & 2 & 3 & 4 & 5 & 6 & 7 & 8 & 9 & 10 \\
\hline Methyl $\beta$-D-glucoside & - & - & + & + & + & + & + & + & + & + \\
\hline Raffinose & - & + & + & + & + & + & + & - & + & - \\
\hline Turanose & - & + & + & - & + & + & + & + & + & + \\
\hline L-Alanine & - & - & - & + & + & + & + & - & + & - \\
\hline L-Alanyl glycine & - & + & - & + & - & + & + & + & + & + \\
\hline L-Glutamic acid & + & - & + & + & + & - & + & + & + & + \\
\hline L-Proline & + & + & - & + & + & - & + & + & + & W \\
\hline L-Serine & - & + & + & - & - & - & + & + & - & - \\
\hline L-Threonine & - & + & - & + & + & - & + & + & - & w \\
\hline 2,3-Butanediol & - & - & - & - & - & + & + & - & - & - \\
\hline Glycerol & - & + & - & + & - & + & + & + & + & + \\
\hline
\end{tabular}

${ }^{\star}$ Data taken from: $a$, Pankratov et al. (2007); b, Urai et al. (2008); c, Luo et al. (2009).

$\dagger$ Reported as negative by Luo et al. (2009).

Table 2. Cellular fatty acid compositions of strain $\mathrm{HMD}_{1056}{ }^{\top}$ and type strains of closely related Mucilaginibacter species

Strains: 1, HMD $1056^{\mathrm{T}}$; 2, M. paludis KACC $13450^{\mathrm{T}}$; 3, M. gracilis KACC $13451^{\mathrm{T}}$; 4, M. kameinonensis KCTC $22227^{\mathrm{T}}$; 5 , M. ximonensis $\mathrm{KCTC}^{22437^{\mathrm{T}}}$ (data in columns 1-5 from this study); 6, M. gossypii Gh-67 ${ }^{\mathrm{T}}$; 7, M. gossypiicola Gh-48 ${ }^{\mathrm{T}}$ (data in columns 6 and 7 from Madhaiyan et al., 2010); 8, M. frigoritolerans $\mathrm{FT}_{2} 2^{\mathrm{T}} ; 9$, M. lappiensis ANJL12 ${ }^{\mathrm{T}}$; 10, M. mallensis MP1X4 ${ }^{\mathrm{T}}$ (data in columns 8-10 from Männistö et al., 2010). All strains were grown for 2 days at $25{ }^{\circ} \mathrm{C}$ on R2A. Values are percentages of total fatty acids. Only fatty acids that account for more than $1 \%$ for one or more strains are indicated. tr, Trace; ND, not detected/not reported.

\begin{tabular}{|c|c|c|c|c|c|c|c|c|c|c|}
\hline Fatty acid & 1 & 2 & 3 & 4 & 5 & 6 & 7 & 8 & 9 & 10 \\
\hline $\mathrm{C}_{14: 0}$ & 2.6 & 1.6 & 1.1 & 1.7 & $\operatorname{tr}$ & 1.2 & 1.7 & $\operatorname{tr}$ & $\operatorname{tr}$ & $\operatorname{tr}$ \\
\hline iso- $\mathrm{C}_{15: 0}$ & 24.4 & 23.2 & 20.6 & 22.9 & 33.2 & 25.8 & 20.0 & 21.9 & 18.9 & 26.0 \\
\hline $\mathrm{C}_{15: 1} \omega 6 c$ & 1.1 & 1.8 & $\operatorname{tr}$ & 1.1 & 3.1 & $\operatorname{tr}$ & $\operatorname{tr}$ & $\mathrm{ND}$ & ND & $\mathrm{ND}$ \\
\hline $\mathrm{C}_{15: 1} \omega 5 c$ & $\mathrm{ND}$ & $\operatorname{tr}$ & ND & ND & ND & 2.8 & 1.3 & 1.1 & ND & $\operatorname{tr}$ \\
\hline $\mathrm{C}_{15: 0}$ & ND & ND & ND & ND & ND & $\mathrm{ND}$ & ND & 1.2 & $\operatorname{tr}$ & 1.3 \\
\hline $\mathrm{C}_{16: 0}$ & 4.5 & 3.7 & 7.9 & 5.8 & 2.3 & 15.0 & 17.0 & 3.1 & 3.7 & 4.8 \\
\hline iso- $\mathrm{C}_{15: 0} 3-\mathrm{OH}$ & 2.9 & 1.7 & 2.0 & 2.6 & 3.7 & 1.9 & 4.5 & 2.9 & 2.2 & 2.9 \\
\hline $\mathrm{C}_{15: 0} 2-\mathrm{OH}$ & ND & 1.2 & $\operatorname{tr}$ & 1.4 & $\operatorname{tr}$ & $\mathrm{ND}$ & $\operatorname{tr}$ & $\operatorname{tr}$ & ND & $\operatorname{tr}$ \\
\hline $\mathrm{C}_{17: 1} \omega 8 c$ & $\mathrm{ND}$ & 1.0 & $\operatorname{tr}$ & $\operatorname{tr}$ & $\operatorname{tr}$ & $\operatorname{tr}$ & $\operatorname{tr}$ & $\mathrm{ND}$ & ND & $\mathrm{ND}$ \\
\hline $\mathrm{C}_{16: 0} 3-\mathrm{OH}$ & 1.4 & $\operatorname{tr}$ & 3.3 & 1.4 & 1.2 & 5.1 & 4.6 & $\operatorname{tr}$ & 3.2 & $\operatorname{tr}$ \\
\hline $\mathrm{C}_{18: 0}$ & $\operatorname{tr}$ & $\operatorname{tr}$ & $\operatorname{tr}$ & $\operatorname{tr}$ & $\mathrm{ND}$ & 1.6 & $\mathrm{ND}$ & $\mathrm{ND}$ & $\mathrm{ND}$ & $\operatorname{tr}$ \\
\hline Summed feature $9^{*}$ & 1.6 & $\operatorname{tr}$ & 1.4 & ND & 4.6 & $\operatorname{tr}$ & $\operatorname{tr}$ & ND & ND & ND \\
\hline
\end{tabular}

${ }^{*}$ Summed features represent groups of two or three fatty acids that could not be separated using the MIDI system. Summed feature 3 comprised iso- $\mathrm{C}_{15: 0} 2-\mathrm{OH}$ and/or $\mathrm{C}_{16: 1} \omega 7 c$ and summed feature 9 comprised iso- $\mathrm{C}_{17: 1} \omega 9 c$ and/or 10-methyl $\mathrm{C}_{16: 0}$. 
arylamidase, trypsin, acid phosphatase, naphthol-AS-BIphosphohydrolase, $\alpha$-galactosidase, $\alpha$-glucosidase, $N$ acetyl- $\beta$-glucosaminidase and $\alpha$-fucosidase activities are present, but lipase (C14), $\alpha$-chymotrypsin, $\beta$-galactosidase, $\beta$-glucuronidase, $\beta$-glucosidase and $\alpha$-mannosidase activities are absent. The following compounds are utilized as sole carbon sources in Biolog GN2 microplates: cellobiose, D-fructose, gentiobiose, $\alpha$-D-glucose, maltose, sucrose, Lglutamic acid and L-proline. The following carbon sources are not utilized: $\alpha$-cyclodextrin, dextrin, glycogen, Tweens 40 and $80, N$-acetyl-D-galactosamine, $N$-acetyl-D-glucosamine, adonitol, L-arabinose, D-arabitol, i-erythritol, Lfucose, D-galactose, myo-inositol, lactose, lactulose, D-mannitol, D-mannose, melibiose, methyl $\beta$-D-glucoside, D-psicose, raffinose, L-rhamnose, D-sorbitol, trehalose, turanose, xylitol, pyruvic acid methyl ester, succinic acid monomethyl ester, acetic acid, cis-aconitic acid, citric acid, formic acid, D-galactonic acid lactone, D-galacturonic acid, D-gluconic acid, D-glucosaminic acid, D-glucuronic acid, $\alpha-, \beta$ - and $\gamma$-hydroxybutyric acids, $p$-hydroxyphenylacetic acid, itaconic acid, $\alpha$-ketobutyric acid, $\alpha$-ketoglutaric acid, $\alpha$-ketovaleric acid, DL-lactic acid, malonic acid, propionic acid, quinic acid, D-saccharic acid, sebacic acid, succinic acid, bromosuccinic acid, succinamic acid, glucuronamide, L-alaninamide, D- and L-alanine, L-alanyl glycine, Lasparagine, L-aspartic acid, glycyl L-aspartic acid, glycyl L-glutamic acid, L-histidine, hydroxy-L-proline, L-leucine, L-ornithine, L-phenylalanine, L-pyroglutamic acid, D- and L-serine, L-threonine, DL-carnitine, $\gamma$-aminobutyric acid, urocanic acid, inosine, uridine, thymidine, phenylethylamine, putrescine, 2-aminoethanol, 2,3-butanediol, glycerol, DL- $\alpha$-glycerol phosphate, $\alpha$-D-glucose 1 -phosphate and D-glucose 6-phosphate. The major fatty acids are summed feature 3 (iso- $\mathrm{C}_{15: 0} 2-\mathrm{OH}$ and/or $\mathrm{C}_{16: 1} \omega 7 c$ ) and iso- $\mathrm{C}_{15: 0}$. The DNA G + C content of the type strain is $46.9 \mathrm{~mol} \%$.

The type strain, HMD $1056^{\mathrm{T}}\left(=\mathrm{KCTC} 22746^{\mathrm{T}}=\mathrm{CECT}\right.$ $7550^{\mathrm{T}}$ ), was isolated from a mesotrophic freshwater lake in Wangsan, Yongin, Gyeonggi, Republic of Korea.

\section{Acknowledgements}

This research was supported by the project on survey and excavation of Korean indigenous species of the National Institute of Biological Resources (NIBR) under the Ministry of Environment, Korea.

\section{References}

An, D. S., Yin, C. R., Lee, S. T. \& Cho, C. H. (2009). Mucilaginibacter daejeonensis sp. nov., isolated from dried rice straw. Int J Syst Evol Microbiol 59, 1122-1125.

Baik, K. S., Park, S. C., Kim, E. M., Lim, C. H. \& Seong, C. N. (2010). Mucilaginibacter rigui sp. nov., isolated from wetland freshwater, and emended description of the genus Mucilaginibacter. Int J Syst Evol Microbiol 60, 134-139.

Bernardet, J. F., Vancanneyt, M., Matte-Tailliez, O., Grisez, L., Tailliez, P., Bizet, C., Nowakowski, M., Kerouault, B. \& Swings, J. (2005). Polyphasic study of Chryseobacterium strains isolated from diseased aquatic animals. Syst Appl Microbiol 28, 640-660.
Cho, J. C. \& Giovannoni, S. J. (2003). Parvularcula bermudensis gen. nov., sp. nov., a marine bacterium that forms a deep branch in the $\alpha$-Proteobacteria. Int J Syst Evol Microbiol 53, 1031-1036.

Chun, J., Lee, J. H., Jung, Y., Kim, M., Kim, S., Kim, B. K. \& Lim, Y. W. (2007). EzTaxon: a web-based tool for the identification of prokaryotes based on $16 \mathrm{~S}$ ribosomal RNA gene sequences. Int J Syst Evol Microbiol 57, 2259-2261.

Collins, M. D. (1985). Analysis of isoprenoid quinones. Methods Microbiol 18, 329-366.

Fautz, E. \& Reichenbach, H. (1980). A simple test for flexirubin-type pigments. FEMS Microbiol Lett 8, 87-91.

Felsenstein, J. (1981). Evolutionary trees from DNA sequences: a maximum likelihood approach. J Mol Evol 17, 368-376.

Felsenstein, J. (1985). Confidence limits on phylogenies: an approach using the bootstrap. Evolution 39, 783-791.

Fitch, W. M. (1971). Toward defining the course of evolution: minimum change for a specific tree topology. Syst Zool 20, 406-416.

Jeon, Y., Lee, S. S., Chung, B. S., Kim, J. M., Bae, J. W., Park, S. K. \& Jeon, C. O. (2009). Mucilaginibacter oryzae sp. nov., isolated from soil of a rice paddy. Int J Syst Evol Microbiol 59, 1451-1454.

Luo, X., Zhang, L., Dai, J., Liu, M., Zhang, K., An, H. \& Fang, C. (2009). Mucilaginibacter ximonensis sp. nov., isolated from Tibetan soil. Int J Syst Evol Microbiol 59, 1447-1450.

MacFaddin, J. F. (1980). Biochemical Tests for Identification of Medical Bacteria, 2nd edn. Baltimore: Williams \& Wilkins.

Madhaiyan, M., Poonguzhali, S., Lee, J. S., Senthilkumar, M., Lee, K. C. \& Sundaram, S. (2010). Mucilaginibacter gossypii sp. nov. and Mucilaginibacter gossypiicola sp. nov., plant-growth-promoting bacteria isolated from cotton rhizosphere soils. Int J Syst Evol Microbiol 60, 2451-2457.

Männistö, M. K., Tiirola, M., McConnell, J. \& Häggblom, M. M. (2010). Mucilaginibacter frigoritolerans sp. nov., Mucilaginibacter lappiensis sp. nov. and Mucilaginibacter mallensis sp. nov., isolated from soil and lichen samples. Int J Syst Evol Microbiol 60, 2849-2856.

Mesbah, M. \& Whitman, W. B. (1989). Measurement of deoxyguanosine/thymidine ratios in complex mixtures by high-performance liquid chromatography for determination of the mole percentage guanine + cytosine of DNA. J Chromatogr A 479, 297-306.

Minnikin, D. E., O’Donnell, A. G., Goodfellow, M., Alderson, G., Athalye, M., Schaal, A. \& Parlett, J. H. (1984). An integrated procedure for the extraction of bacterial isoprenoid quinones and polar lipids. J Microbiol Methods 2, 233-241.

Pankratov, T. A., Tindall, B. J., Liesack, W. \& Dedysh, S. N. (2007). Mucilaginibacter paludis gen. nov., sp. nov. and Mucilaginibacter gracilis sp. nov., pectin-, xylan- and laminarin-degrading members of the family Sphingobacteriaceae from acidic Sphagnum peat bog. Int J Syst Evol Microbiol 57, 2349-2354.

Saitou, N. \& Nei, M. (1987). The neighbor-joining method: a new method for reconstructing phylogenetic trees. Mol Biol Evol 4, 406-425.

Sasser, M. (1990). Identification of bacteria by gas chromatography of cellular fatty acids, MIDI Technical Note 101. Newark, DE: MIDI Inc.

Tamura, K., Dudley, J., Nei, M. \& Kumar, S. (2007). MEGA4: molecular evolutionary genetics analysis (MEGA) software version 4.0. Mol Biol Evol 24, 1596-1599.

Urai, M., Aizawa, T., Nakagawa, Y., Nakajima, M. \& Sunairi, M. (2008). Mucilaginibacter kameinonensis sp., nov., isolated from garden soil. Int J Syst Evol Microbiol 58, 2046-2050.

Wayne, L. G., Brenner, D. J., Colwell, R. R., Grimont, P. A. D., Kandler, O., Krichevsky, M. I., Moore, L. H., Moore, W. E. C., Murray, R. G. E. \& other authors (1987). International Committee on Systematic Bacteriology. Report of the ad hoc committee on reconciliation of approaches to bacterial systematics. Int J Syst Bacteriol 37, 463-464. 